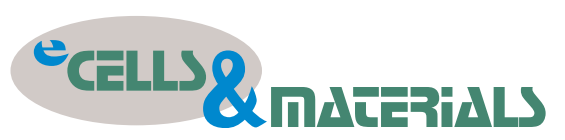

\title{
LENTIVIRAL-B ASED REPORTER CONSTRUCTS FOR PROFILING CHONDROGENIC ACTIVITY IN PRIMARY EQUINE CELL POPULATIONS
}

\author{
A. Martin-Pena ${ }^{1}$, R.M. Porter ${ }^{2}$, G. Plumton 3 , T.M. McCarrel ${ }^{4}$, A.J. Morton ${ }^{4}$, M.V. Guijarro ${ }^{5}$, \\ S.C. Ghivizzani ${ }^{1}$, B. Sharma ${ }^{2}$ and G.D. Palmer ${ }^{1, *}$ \\ ${ }^{1}$ Department of Orthopaedics and Rehabilitation, University of Florida, Gainesville, FL, USA \\ ${ }^{2}$ Department of Orthopaedics, University of Arkansas, Little Rock, AR, USA \\ ${ }^{3}$ Department of Biomedical Engineering, University of Florida, Gainesville, FL, USA \\ ${ }^{4}$ College of Veterinary Sciences, University of Florida, Gainesville, FL, USA \\ ${ }^{5}$ Department of Anatomy and Cell Biology, University of Florida, Gainesville, FL, USA
}

\begin{abstract}
Successful clinical translation of mesenchymal stem cell (MSC)-based therapies for cartilage repair will likely require the implementation of standardised protocols and broadly applicable tools to facilitate the comparisons among cell types and chondroinduction methods. The present study investigated the utility of recombinant lentiviral reporter vectors as reliable tools for comparing chondrogenic potential among primary cell populations and distinguishing cellular-level variations of chondrogenic activity in widely used threedimensional (3D) culture systems. Primary equine MSCs and chondrocytes were transduced with vectors containing combinations of fluorescent and luciferase reporter genes under constitutive cytomeglavirus (CMV) or chondrocyte-lineage (Col2) promoters. Reporter activity was measured by fluorescence imaging and luciferase assay. In 3D cultures of MSC aggregates and polyethylene glycol-hyaluronic acid (PEG-HA) hydrogels, transforming growth factor beta 3 (TGF- 33 )-mediated chondroinduction increased Col2 reporter activity, demonstrating close correlation with histology and mRNA expression levels of COL2A1 and SOX9. Comparison of chondrogenic activities among MSC populations using a secretable luciferase reporter revealed enhanced chondrogenesis in bone-marrow-derived MSCs relative to MSC populations from synovium and adipose tissues. A dual fluorescence reporter - enabling discrimination of highly chondrogenic (Col2GFP) cells within an MSC population (CMV-tdTomato) - revealed marked heterogeneity in differentiating aggregate cultures and identified chondrogenic cells in chondrocyte-seeded PEG-HA hydrogels after 6 weeks in a subcutaneous implant model - indicating stable, long-term reporter expression in vivo. These results suggested that lentiviral reporter vectors may be used to address fundamental questions regarding chondrogenic activity in chondroprogenitor cell populations and accelerate clinical translation of cell-based cartilage repair strategies.
\end{abstract}

Keywords: Mesenchymal stem cell, chondrogenesis/cartilage repair, lentiviral reporter construct, Col2 promoter, fluorescence imaging, live-cell monitoring, tissue engineering/regenerative medicine, 3D culture.

*Address for correspondence: Glyn Palmer, PhD, Department of Orthopaedics and Rehabilitation, University of Florida, 1600 SW Archer Rd, MSB, M2-235, Gainesville, FL, 32610, USA.

Telephone number: +13522737087 Fax number: +13522737427 Email: glynpal@gmail.com

Copyright policy: This article is distributed in accordance with Creative Commons Attribution Licence (http://creativecommons.org/licenses/by-sa/4.0/).

\section{Introduction}

For over two decades, adult mesenchymal stem/ progenitor cells (MSCs) have been regarded as highly preferable cell type for autologous cell-based cartilage repair ( Matsumoto et al., 2010; Roelofs et al., 2013). Their prevalence in many tissues, high expansion potential and accessibility overcome many of the problems associated with the use of articular chondrocytes, including limited availability, donor site morbidity and phenotypic instability (Jayasuriya et al., 2015; Matricali et al., 2010). However, the clinical advancement of MSC and other cell-based therapies for cartilage repair is hindered by the wide variation in pre-clinical models used among laboratories and associated differences in cell culture, differentiation 
protocols and implantation strategies (Goldberg et al., 2017). As a result, despite numerous reports of improved healing in animal studies (Bornes et al., 2014; Goldberg et al., 2017; Huang et al., 2017; Lo Monaco et al., 2018), there is still no consensus regarding the efficacy of the used strategies and a clear pathway to clinical translation has yet to emerge. Within the MSC field, this disparity is exacerbated by the poor characterisation of primary cell populations and the lack of standardised tools for quantifying chondrogenic potential and cartilage repair. In particular, using current techniques, it is difficult to determine if MSCs uniformly undergo chondrogenesis or directly participate in neocartilage formation in vivo.

A consensus regarding which autologous cell sources, chondrocytes or various MSC subtypes, are most useful for cartilage repair has yet to be established. MSCs from bone marrow (Johnstone et al., 1998; Mackay et al., 1998), fat (Khan et al., 2012; Nathan et al., 2003; Veronesi et al., 2013; Wickham et al., 2003) and synovium (Pei et al., 2008; Sakaguchi et al., 2005; Shirasawa et al., 2006) are widely investigated and purportedly enhanced chondrogenic activity is reported for synovial-derived MSCs (Sakaguchi et al., 2005; Yoshimura et al., 2007) and cartilagederived stem cells (McCarthy et al., 2012; Williams et al., 2010). However, the lack of universally adopted methods for assessing chondrogenic potential prevents meaningful study-to-study comparisons. Histology-based assessments of MSC chondrogenesis in vitro and in vivo are essential for visualising cartilage ECM components and the nature of chondrocyte differentiation but provide limited sensitivity for meaningful quantitative comparisons of chondrogenesis among different cell preparations (Orth et al., 2015). On the other hand, biochemical and molecular measurement of chondrocyte markers or ECM synthesis offer quantitative measures but often require pooling of samples and do not distinguish cellular-level responses (McLeod et al., 2017).

Transcriptional reporter systems comprised of fluorescent or bioluminescent cDNAs under regulatory control of promoters or response elements of chondrocyte marker genes, including $A C A N$ (Hung et al., 2000; Palmer et al., 2001) COL11A2 (Outani et al., 2013) and COL2A1 (Kan et al., 2009; Padmashali et al., 2014; Porter et al., 2012; Stokes et al., 2001), are used as quantitative indicators of chondrocyte activity in cell culture and transgenic models. However, their application as tools to monitor cartilage differentiation and repair in cell and tissue engineering protocols has not been explored. In the present study, the utility of lentiviral-vector-based transcriptional reporter constructs that incorporate a modified collagen type 2 (Col2) promoter was explored for the evaluation of chondrogenesis of post-natal, primary equine MSCs and chondrocytes. The vectors, containing bicistronic or independent expression cassettes encoding combinations of fluorescence and luciferase-based reporters, were used to demonstrate chondrocyte- specific activity and evaluate chondrogenic potential within and among primary cell populations. Reporter activity was measured by fluorescence imaging, flow cytometry or luciferase assay in widely used cell aggregate and hydrogel culture models of chondrogenesis and validated by conventional assessments of chondrogenic differentiation. The utility of these reporters for assessment of cell fate after in vivo implantation was also evaluated.

\section{Materials and Methods}

\section{Generation of recombinant lentiviral reporter vectors}

Bicistronic lentiviral vector- Lv.Col2-GFP/fLuc

A promoter sequence was synthesised based on a previous design (Kan et al., 2009): four repeats of a highly conserved enhancer region within the first intron of COL2A1 (+2126/+ $2174 \mathrm{bp})$, which contains a SOX9 binding motif (Zhou et al., 1998), were positioned upstream of the core COL2A1 promoter (-164/+ $37 \mathrm{bp})$. These regulatory sequences were flanked by the restriction sites for SpeI ( $5^{\prime}$ end) and BamHI ( $3^{\prime}$ end) and an NheI site was placed between the four enhancer repeats and the core COL2A1 promoter. This promoter was synthesised by GenScript (Piscataway, NJ, USA) and cloned in place of a truncated, "minimal" cytomegalovirus (mCMV) promoter within the third-generation lentiviral expression plasmid pTRH1-mCMVdscGFP-T2A-Fluc (System Biosciences, Mountain View, CA, USA). In the resulting reporter construct, pGF-4eCOL2A1 (Addgene ID\# 97210; Addgene, Cambridge, MA, USA), the promoter drives the co-expression of copepod green fluorescent protein (copGFP) and firefly luciferase using the Thosea asigna virus 2A (T2A) self-cleaving peptide (Kim et al., 2011). Replication-deficient lentivirus was generated by transfecting 293T cells with pGF-4eCOL2A1 and the third-generation packaging plasmids pMDLg/ pRRE (Addgene ID\# 12251), pRSV-Rev (Addgene ID\# 12253) and pMD2.G (Addgene ID\# 12259) (Dull et al., 1998).

Dual promoter reporter vectors - Lv.CMV-mLuc/EF1GFP, Lv.Col2-mLuc/EF1-GFP and Lv.CMV-tom/Col2GFP

For generation of dual lentiviral reporter vectors with independent expression cassettes under separate regulation of constitutive (CMV or EF1 $\alpha$ ) and chondrogenic (Col2) promoters, the $\mathrm{pcDH}$ lentiviral expression system (System Biosciences) was used. A modified pcDH lentiviral expression plasmid, pcDH-CMV-mLuc/EF1-GFP, containing independent CMV-mLuc and EF1-GFP expression cassettes was generated by cloning the full-length cDNA of Metridia luciferase (mLuc) from the pMetLuc reporter vector (Takara Bio, Mountain View, CA; USA) into the multiple cloning site of pcDH-CMV-MCS-EF1-copGFP using compatible 
Table1. Primers sequences to generate a pcDH-CMV-tom/Col2-GFP lentiviral expression plasmid.

\begin{tabular}{|c|c|}
\hline Primer sequence & Orientation \\
\hline 5'-TTATCGATGCGGCCGCGAACTAGTCTGTGAATCG-3' & forward \\
\hline 5'-CGCATGTTAGTCGACTTCCTCTGCCCTCACCG-3' & reverse \\
\hline
\end{tabular}

BamHI/NotI restriction sites. To generate a lentiviral expression plasmid with mLuc under control of a Col2 promoter, pcDH-Col2-mLuc/EF1-GFP, the CMV promoter sequence was removed from pcDH-CMVmLuc/EF1-GFP and replaced with the Col2 promoter sequence from pGF-4eCOL2A1 using compatible SpeI/BamHI restriction sites. For generation of a dual fluorescence reporter containing independent CMV-tom and Col2-GFP expression cassettes, the full-length cDNA of tdTomato was obtained by BamHI/NotI digestion of pCSCMV:tdTomato (Addgene ID\# 30530) and cloned into the multiple cloning site of $\mathrm{pcDH}$ to generate pcDH-CMV-tom/ EF1-GFP. Then, the EF1-GFP cassette was replaced with a Col2-GFP expression cassette flanked by NotI ( $5^{\prime}$ end; underlined in the primer sequence) and SalI ( $3^{\prime}$ end; underlined in the primer sequence) restriction sites, introduced by PCR amplification of pGF-4eCOL2A1 using the primers listed in Table 1, to generate a $\mathrm{pcDH}$-CMV-tom/Col2-GFP lentiviral expression plasmid. For production of replicationdeficient lentiviral vectors, each $\mathrm{pcDH}$ lentiviral expression plasmid was transfected into 293T cells with the second generation packaging plasmids pSPAX-2 (Addgene ID\# 12260) and pMD2.G. Viral supernatants were harvested $48 \mathrm{~h}$ after transfection and either used directly for cell transduction or concentrated to $1 / 50$ th of the initial volume using the Lenti-X concentrator reagent and protocol (Takara).

\section{Viral-titering}

Quantitation of lentiviral vectors from culture supernatants or concentrated virus was performed using the QuickTiter ${ }^{\mathrm{TM}}$ Lentivirus Titer Kit (Cell Biolabs, San Diego, CA, USA). Physical titers were determined based on the detection of lentivirusassociated HIV p24 and ranged from $2.5 \times 10^{9}-$ $2 \times 10^{10} \mathrm{vp} / \mathrm{mL}$.

\section{Cell and tissue harvest}

Cartilage, bone-marrow, synovium and adipose tissues were collected from horses (age range: 2-12 years) euthanised for health issues unrelated to musculoskeletal conditions at the UF School of Veterinary Medicine, Gainesville, FL, USA.

\section{Articular chondrocytes}

Intact, healthy cartilage was obtained from the femoropatellar, metacarpophalangeal and scapulohumeral joints, minced finely and digested with $0.2 \%$ collagenase type II (Worthington, Biochemical Corporation, Lakewood, NJ, USA) for 12$16 \mathrm{~h}$ at $37^{\circ} \mathrm{C}, 5 \% \mathrm{CO}_{2}$ in DMEM/F12 (ThermoFisher Scientific) supplemented with $5 \%$ foetal bovine serum (FBS) (Hyclone Laboratories, South Logan, UT, USA). Cell suspensions were filtered through a $70 \mu \mathrm{m}$ strainer and plated at density of 50,000 cells $/ \mathrm{cm}^{2}$ in high glucose Dulbecco's modified Eagle medium (DMEM) (Corning) supplemented with $10 \%$ FBS. Within $3 \mathrm{~d}$ of harvest, primary chondrocytes were replated at $80 \%$ confluence until required.

\section{Synoviocytes}

The non-collagenous soft tissues, including the synovial lining and subsynovium, were scraped from the capsular tissues of the carpal joints, minced and digested in saline solution with $0.2 \%$ collagenase for $2 \mathrm{~h}$ at $37{ }^{\circ} \mathrm{C}$ and $5 \% \mathrm{CO}_{2}$, as previously described (Watson et al., 2013). Non-adherent cells were removed after $24 \mathrm{~h}$ and, after 1 week, cells were replated at high density until required.

\section{Bone-marrow-derived MSCS}

Bone marrow aspirate $(\sim 15 \mathrm{~mL})$ was obtained by needle puncture of the iliac crest, mixed $1: 1$ with MSC isolation medium [low glucose DMEM with $20 \%$ FBS and $10 \mathrm{ng} / \mathrm{mL}$ fibroblast growth factor 2 (FGF-2) (Peprotech)] and plated at 500,000 nucleated cells $/ \mathrm{cm}^{2}$. After $3 \mathrm{~d}$, the media was replaced with MSC expansion medium (low glucose DMEM supplemented with $10 \% \mathrm{FBS}$ and $10 \mathrm{ng} / \mathrm{mL}$ FGF-2) and the cells were cultured until reaching confluency $(\sim 10 \mathrm{~d})$.

\section{Synovial-derived MSCS}

$\sim 2-3 \mathrm{~g}$ of synovial tissue were harvested from the intercarpal and femoropatellar joints and digested with $0.1 \%$ trypsin in phosphate buffered saline (PBS) for $30 \mathrm{~min}$ followed by treatment for $2 \mathrm{~h}$ at $37^{\circ} \mathrm{C}$ and $5 \% \mathrm{CO}_{2}$ with $0.1 \%$ collagenase in serum-free high glucose DMEM, as previously described (He et al., 2009). After digestion, cells were filtered through a $45 \mu \mathrm{m}$ strainer and plated until confluency was reached $(\sim 7 \mathrm{~d})$.

\section{Adipose-derived MSCs}

$\sim 8-10 \mathrm{~g}$ of adipose tissue were harvested from the subcutaneous fat depot lateral to the tail head. The tissue was diced into small pieces and digested for $3 \mathrm{~h}$ at $37^{\circ} \mathrm{C}, 5 \% \mathrm{CO}_{2}$ with $0.2 \%$ collagenase in serum-free DMEM. After digestion, cells were filtered through a $45 \mu \mathrm{m}$ strainer and plated until confluency $(\sim 7 \mathrm{~d})$. After initial plating in T-75 flasks (P0), all MSC populations were expanded at 5,000 cells $/ \mathrm{cm}^{2}$ in MSC expansion medium until required.

To verify the colony-forming potential of MSC populations, primary cell isolates were plated into 6-well plates and cultured in MSC expansion 
medium. After $10 \mathrm{~d}$, colonies were fixed with $10 \%$ neutral buffered formalin (NBF) for $15 \mathrm{~min}$ and stained with $1 \%$ crystal violet for $1 \mathrm{~h}$ at room temperature. Colony numbers per $10^{3}$ nucleated cells were as follows: $0.02 \pm 0.002 \mathrm{BM}-\mathrm{MSC}$; $12 \pm 3.2$ S-MSCs; $2.9 \pm 1.8$ A-MSCs.

\section{Lentiviral transduction}

Primary cells (passage 2-4) were seeded into 6-well plates and the culture media replaced with $1 \mathrm{~mL} /$ well serum-free DMEM containing $8 \mu \mathrm{g} / \mathrm{mL}$ polybrene (Sigma-Aldrich) and 293T viral supernatants or concentrated virus. For transduction, cells were infected (dose range: $1.3 \times 10^{3}-6.4 \times 10^{3} \mathrm{vp} /$ cell) by centrifugation at 1,200 $\times g$ for $60 \mathrm{~min}$, followed by an additional $2 \mathrm{~h}$ in a tissue culture incubator at $37^{\circ} \mathrm{C}$, $5 \% \mathrm{CO}_{2}$. Then, the virus-containing medium was removed and replaced with growth medium and cells were replated into T-150 flasks until required. Transduction efficiencies, determined by tdTomato or GFP flow cytometry, were $~ 70 \%$ or higher for all viral vectors and cell types used in the study. At the vector doses used, impaired chondrogenic activity of equine MSCs were not observed (data not shown).

\section{In vitro chondrogenesis \\ Aggregate culture}

Lentiviral-reporter-labelled MSCs and chondrocytes were trypsinised from monolayer cultures and seeded at $5 \times 10^{5}$ cells $/ \mathrm{mL}$ in $15 \mathrm{~mL}$ polypropylene tubes, centrifuged at $500 \times g$ for 5 min to induce aggregate formation and maintained in $0.5 \mathrm{~mL}$ of chondrogenic medium consisting of serum-free, high glucose DMEM containing pyruvate $(1 \mathrm{mM}), 1 \%$ ITS ${ }^{\text {TM }}$ Premix (BD Biosciences), $37.5 \mu \mathrm{g} / \mathrm{mL}$ ascorbate 2-phosphate and $10^{-7} \mathrm{M}$ dexamethasone (Johnstone et al., 1998). To induce chondrogenesis, media was supplemented with $10 \mathrm{ng} / \mathrm{mL}$ human transforming growth factor beta 3 (TGF- $\beta 3$; Peprotech).

\section{Photopolymerisable PEG-HA hydrogels}

Labelled cells $\left(2 \times 10^{7}\right.$ cells $\left./ \mathrm{mL}\right)$ were mixed with a polymer solution of $10 \% \mathrm{w} / \mathrm{v}$ PEODA (Laysan Bio, Arab, AL, USA), $0.05 \%$ w/v Irgacure 2959 photoinitiator (Sigma-Aldrich) and $2.5 \mathrm{mg} / \mathrm{mL}$ hyaluronic acid (1,100 kDa; Lifecore Biomedical) in sterile PBS (Sharma et al., 2007). Next, the cell-polymer solution was pipetted into plastic moulds and placed under a long-wave, $365 \mathrm{~nm}$ ultraviolet light at $4 \mathrm{~mW} / \mathrm{cm}^{2}$ (Omincure S2000, Excelitas Technologies, Mississauga, ON, Canada) for $5 \mathrm{~min}$ to induce polymerisation and generate $5 \times 3 \mathrm{~mm}$ cylindrical constructs. Then, the constructs were transferred into 24-well plates filled with chondrogenic medium for in vitro studies or implantation experiments.

\section{Subcutaneous implantation}

All procedures involving animals were conducted according to protocols approved by the University of Florida Institutional Animal Care and Use Committee. For surgery, athymic nude mice
(Charles River) were anaesthetised by isofluorane inhalation and prepped for surgery following sedation. Under aseptic conditions, subcutaneous pockets were made by generating two $10 \mathrm{~mm}$-long dorsal midline incisions and gently spreading the cutaneous tissue lateral to each incision line creating a total of 4 pockets per animal. Then, sterile cell-seeded polyethylene glycol-hyaluronic acid (PEG-HA) scaffolds, approximately $5 \mathrm{~mm}$ in diameter, $3 \mathrm{~mm}$ thick, were securely implanted into each pocket away from the incision area. Following wound closure using wound clips, the animals were removed from anaesthesia and returned to free cage activity for the duration of the experiments.

\section{Flow cytometry and cell sorting}

For assessment of transfection efficiency of Lv.Col2-GFP/fLuc and Lv.CMV-GFP/fLuc vectors, monolayer cultures were trypsinised, washed in PBS and resuspended in PBS/0.05\% bovine serum albumin (BSA) at $5 \times 10^{6}$ cells $/ \mathrm{mL}$. GFP fluorescence was analysed using an LSRII flow cytometer (BD BioSciences). For sorting of GFP+/tdTomato + and GFP-/tdTomato+ subpopulations in differentiating BM-MSC aggregates by fluorescence-activated cell sorting (FACS), Lv.CMV-tom/Col2-GFP-transduced aggregates were pooled $(n=7-8)$ and digested with a mixture of $0.1 \%$ collagenase and Tryple Select Enzyme (ThermoFisher Scientific) for $45 \mathrm{~min}$ at $37^{\circ} \mathrm{C}$. Recovered cells were resuspended in sterile PBS $/ 0.05 \%$ BSA at $5 \times 10^{6}$ cells $/ \mathrm{mL}$ and stained using a LIVE/DEAD ${ }^{\mathrm{TM}}$ Fixable Blue Cell Dead Stain Kit (Molecular Probes ${ }^{\mathrm{TM}}$ ) prior to sorting, according to the manufacturer's protocol. Cell sorting was performed on a BDFACSAria II Cell Sorter (Beckton Dickinson) by first selecting for viable cells emitting low fluorescence under UV excitation, prior to gating under green and red channels to separate GFP+/tdTomato+ and GFP-/tdTomato+ populations. Collected cells were immediately transferred to TRIzol (Invitrogen) after sorting for RNA extraction.

\section{Luciferase assay}

Firefly

Assay of Lv.Col2-GFP/fLuc and Lv.CMV-GFP/fLuc transduced monolayer cultures was performed on a Zylux tube luminometer using the Luciferase Assay System (Promega).

\section{Metridia}

Secreted luciferase from conditioned media supernatants of Lv.Col2mLuc/EF1-GFP- and Lv.CMVmLuc/EF1-GFP-transduced cultures was assayed using the Ready-To-Glow ${ }^{\mathrm{TM}}$ Luciferase Reporter Assay (Takara Bio).

\section{RT-PCR}

To measure relative mRNA levels, total RNA was extracted from either pooled aggregates $(n=5)$ and hydrogels $(n=2)$ after $21 \mathrm{~d}$ of chondrogenic induction or sorted cell populations, by phenol:chloroform 
Table2. Primers sequences for RT-qPCR. F: forward primer; R: reverse primer.

\begin{tabular}{|c|c|c|}
\hline Gene & Sequence & Species \\
\hline \multirow{2}{*}{ COL2A1 } & F: 5'-CTGGTCTCAAAGGCGAACAAG-3' & \multirow{2}{*}{ Equine } \\
\hline & R: 5'-GCACCTCTTTTGCCTTCTTCAC-3' & \\
\hline \multirow{2}{*}{ SOX9 } & F: 5'-CAGGTGCTCAAGGGCTACGA-3' & \\
\hline & R: 5'-GACGTGAGGCTTGTTCTTGCT-3' & \\
\hline \multirow{2}{*}{ RPLPO } & F: 5'-CTGATTACACCTTCCCACTTGCT-3' & \\
\hline & R: 5'-AGCCACAAATGCAGATGGATCA-3' & \\
\hline \multirow{2}{*}{$18 S$} & F: 5'-CGGCTTTGGTGACTCTAGATAACC-3' & \\
\hline & R: 5'-CCATGGTAGGCACAGCGACTA-3' & \\
\hline \multirow{2}{*}{ GFP } & F: 5'-GTGGACAGCCACATGCACTT-3' & \multirow{2}{*}{ Copepod } \\
\hline & R: 5' - GTGCTGGTACTCCACGATGC-3' & \\
\hline
\end{tabular}

extraction using TRIzol reagent and isopropanol precipitation. cDNA was synthesised from $1 \mu \mathrm{g}$ of total RNA using the High Capacity RNA-tocDNA kit (Applied Biosystems) and random hexamer primers, according to the manufacturer's instructions. Real-Time PCR amplification of diluted cDNA products was performed on an Eppendorf Realplex Mastercycler using PerFecta SYBR Green MasterMix (QuantaBio, Beverly, MA, USA) and primers designed from equine gene sequences (Table 2). Relative gene expression was determined from $C_{t}$ values by normalising to the housekeeping gene, $18 S$, using the $2^{-\Delta \Delta \mathrm{Ct}}$ method (Livak and Schmittgen, 2001).

\section{Confocal imaging}

\section{Single photon}

Cellular aggregates and PEG hydrogels were fixed in $4 \%$ paraformaldehyde for $30 \mathrm{~min}$ at room temperature, washed 3 times in PBS and mounted in Vectashield (Vector Labs). Samples were imaged using a Leica TCS-SP5 (Leica) equipped with a motorised inverted DM IRE2 microscope (Leica). Serial optical sections $(1024 \times 1024$ pixels $)$ were taken at $4 \mu \mathrm{m}$ intervals using a $20 \times$ objective. For aggregates, specimens were imaged using a previously established protocol for intact tissues (Martin-Pena et al., 2006), covering a total volume of $150 \times 150 \times 150 \mu \mathrm{m}$. For PEG-HA hydrogels, the same volume was scanned in multiple locations within the three-dimensional (3D) construct and regions of interest were randomly selected within each location. Individual channels were set for imaging GFP and tdTomato fluorescence signals. For each channel, confocal settings were maintained throughout the samples to allow comparison.

\section{Multi-photon}

For full depth, spatial assessment of chondrogenic cells at high resolution, day 21 aggregates were imaged using a Nikon A1RMPsi-STORM 4.0 multiphoton, super resolution imaging system (Nikon Instruments). Aggregates were cut in half and scanned using a $20 \times$ objective using a mosaic of 3 by 3 images $(1024 \times 1024$ pixels each $)$ with $10 \%$ overlap in each z-plane, with each z-plane interspaced by $4 \mu \mathrm{m}$ and covering a total volume of $1500 \times 1500 \times 1500 \mu \mathrm{m}$.

\section{Analysis}

Images were processed using ImageJ software (NIH). Chondrogenic cell distribution in aggregates was determined using maximal z-stack projections and the line profile tool to measure pixel intensity ws. depth in the red and green channels. Values were plotted as normalised green:red signal intensity vs. depth. Cell counting in PEG-HA hydrogels was performed using the ImageJ cell count plug-in to determine total cell number and mean fluorescence values in red and green channels.

\section{Histology}

Aggregates and hydrogels were fixed in $10 \% \mathrm{NBF}$ for $30 \mathrm{~min}$ at room temperature and embedded in $0.7 \%$ agarose for ease of handling. After dehydration in graded alcohols, the samples were paraffinembedded and sectioned to $5 \mu \mathrm{m}$ thickness. Sections representing the centre of each sample were stained using $1 \%$ toluidine blue (Sigma-Aldrich) for the detection of matrix proteoglycan.

\section{Statistical analysis}

Quantitative results were shown as representative measurements of a single donor or mean \pm standard deviation of biological replicates or multiple donors $(n=3)$. Statistical significance was determined by twotailed unpaired $t$-test (Fig. 1 and Fig. 5) or two-way ANOVA and subsequent Bonferroni post-hoc test (Fig. 4) using GraphPad Prism 5.0. For all tests, $p<0.05$ was considered statistically significant.

\section{Results}

Chondrocyte specific activity of a modified Col2 promoter in primary equine cells

To investigate the activity of the Col2 promoter in equine cells, a bicistronic lentiviral vector (Lv.Col2GFP/fLuc) was generated, containing the promoter driving co-expression of copepod GFP and firefly 
a
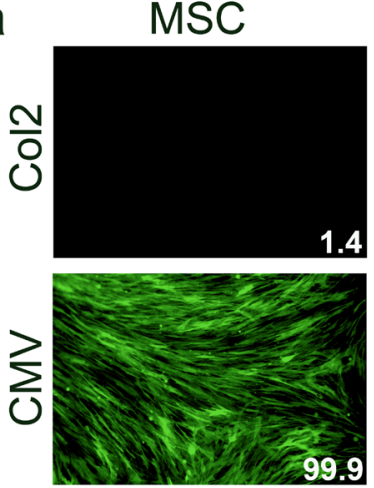

d

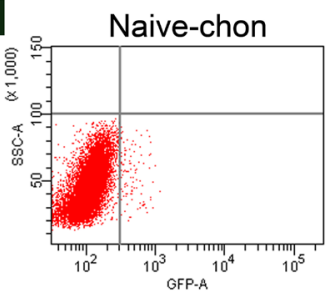

Synoviocyte
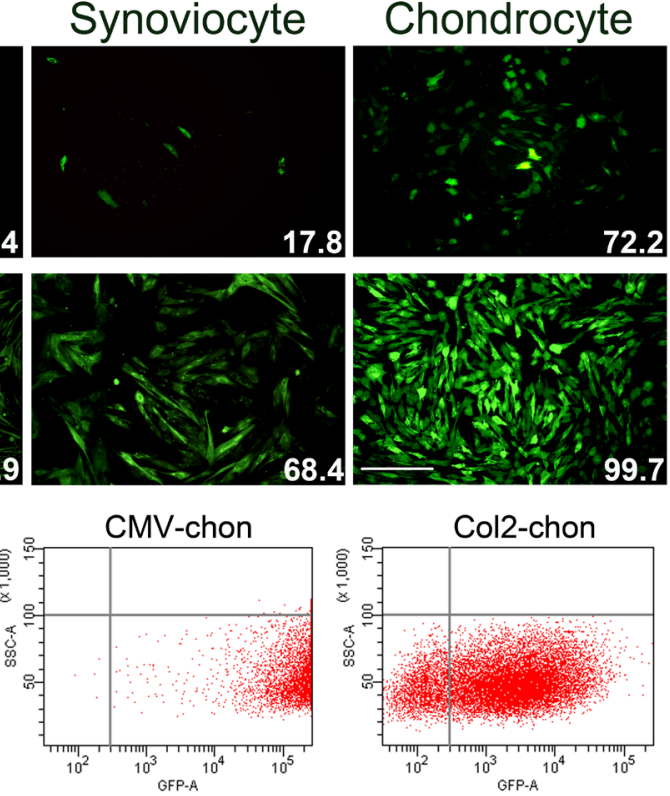

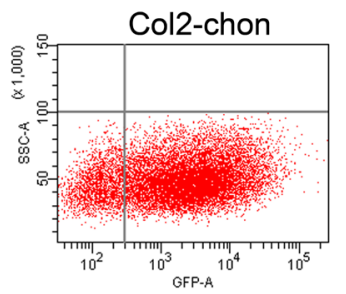

b

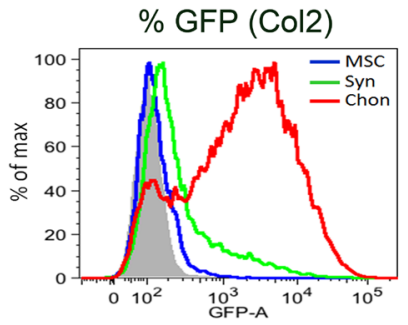

C
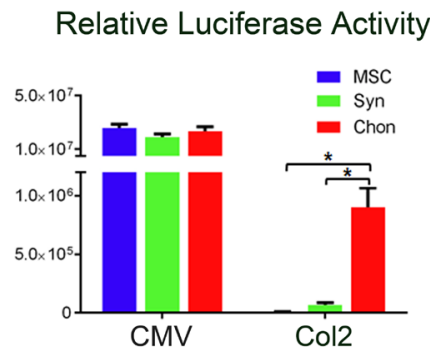

Fig. 1. A modified Col2 promoter exhibited chondrocyte-specific activity in primary equine cells. (a) Green fluorescence images of equine monolayer cultures infected with Lv.Col2-GFP/fLuc (Col2) or Lv.CMVGFP/fLuc (CMV). Numbers indicate percentage of GFP+ cells as measured by flow cytometry. Scale bar: $250 \mu \mathrm{m}$. (b) Histogram flow cytometry plot showing the proportion of GFP+ cells after Lv.Col2-GFP/fLuc transduction (grey: naïve cell control). (c) Relative luciferase activity among same cell populations. (d) Scatter flow cytometry plots showing cell-to-cell variations in GFP fluorescence in Lv-infected chondrocytes. All analyses were performed $72 \mathrm{~h}$ after viral transduction. ${ }^{*} p<0.05 v s$. synoviocytes and MSC.

luciferase and responding to chondrogenic induction of human MSCs (Porter et al., 2012). Monolayer cultures of equine MSCs, synovial fibroblasts and chondrocytes were infected and $\mathrm{Col} 2$ reporter activity was compared to a control lentiviral construct where GFP is driven by a constitutive CMV promoter (Lv.CMV-GFP/fLuc) (Fig. 1). As expected, CMVmediated expression of GFP was high in all cultures: analysis of fluorescence by flow cytometry showed that $\sim 68-100 \%$ of the cells were positive (Fig. 1a,b). In contrast, Col2-mediated GFP expression was present in $72 \%$ of primary chondrocytes and $18 \%$ of synoviocytes but absent in undifferentiated MSCs (Fig. 1a,b). Assay of firefly luciferase in cell lysates revealed the same trend, with chondrocytes exhibiting significantly higher activity $(>10$-fold) than synoviocytes and MSCs ( ${ }^{*} p<0.001 ;$ Fig. 1c). Cell-tocell variations within the Col2-GFP+ population were also detected by flow cytometry (scatter plot; Fig. 1d). While Lv.CMV-GFP/fLuc-transduced chondrocytes were highly positive for GFP with relatively small variation in fluorescence intensity (middle panel; Fig. 1d), Lv.Col2-GFP/fLuc-transduced cultures contained both a negative population and a GFP fluorescence that varied over 2 orders of magnitude (right panel; Fig. 1d). Given the relative uniformity of transduction indicated by Lv.CMV-GFP/fLuc, it was concluded that heterogeneity within the Col2-GFP+ population was attributable to cells with varying chondrogenic activities. Based on these findings, Col2-driven reporter activity was further explored as a sensitive readout for chondrogenesis in 3D culture of primary equine cell populations.

Dual fluorescence reporting revealed heterogeneity within differentiating MSC aggregates

To assess the degree of uniformity of chondrogenesis and visualise temporal, cell-to-cell variations in chondrogenic activity within an MSC population, a dual-fluorescence reporter, Lv.CMV-tom/Col2GFP, was generated. This reporter vector contained independent expression cassettes under separate regulation of CMV (tdTomato) and modified $\mathrm{Col} 2$ (GFP) promoters, enabling the identification of chondrogenic and non-chondrogenic cells within differentiating cell populations. BM-MSCs were transduced with the vector, seeded in aggregate cultures and analysed by confocal microscopy for red and green fluorescence following TGF- $\beta 3$ stimulation at day 7, 14 and 21 (Fig. 2a, upper panels). Z-stack projections of intact aggregates by single photon microscopy revealed abundant tdTomato (red) fluorescence at all time points, indicating high expression of the constitutive CMV-driven reporter. Col2-promoter activation, indicated by either green or a merging of green and red fluorescence (orange), was evident in both unstimulated and day-7-stimulated cultures and identified isolated chondrogenic cells sparsely populated throughout the aggregate. At day 14 and 21, GFP expression markedly increased 
with culture duration, but distinct regions of red fluorescence were still visible, indicating the persistence of non-chondrogenic cells. Supporting these findings, toluidine blue metachromasia increased with culture duration in response to TGF- 33 treatment (Fig. 2a, lower panels), reflecting ECM accumulation. However, even at 3 weeks, staining was negligible in some areas, consistent with little or no cellular differentiation. Together, these observations revealed striking variations of cellular-level chondrogenic activity within an MSC population in 3D aggregate culture.

To confirm enhanced chondrogenic activity of GFP-expressing cells in differentiating aggregates, cells were isolated by enzymatic digestion after $14 \mathrm{~d}$ in culture, separated into tdTomato+/GFP- and
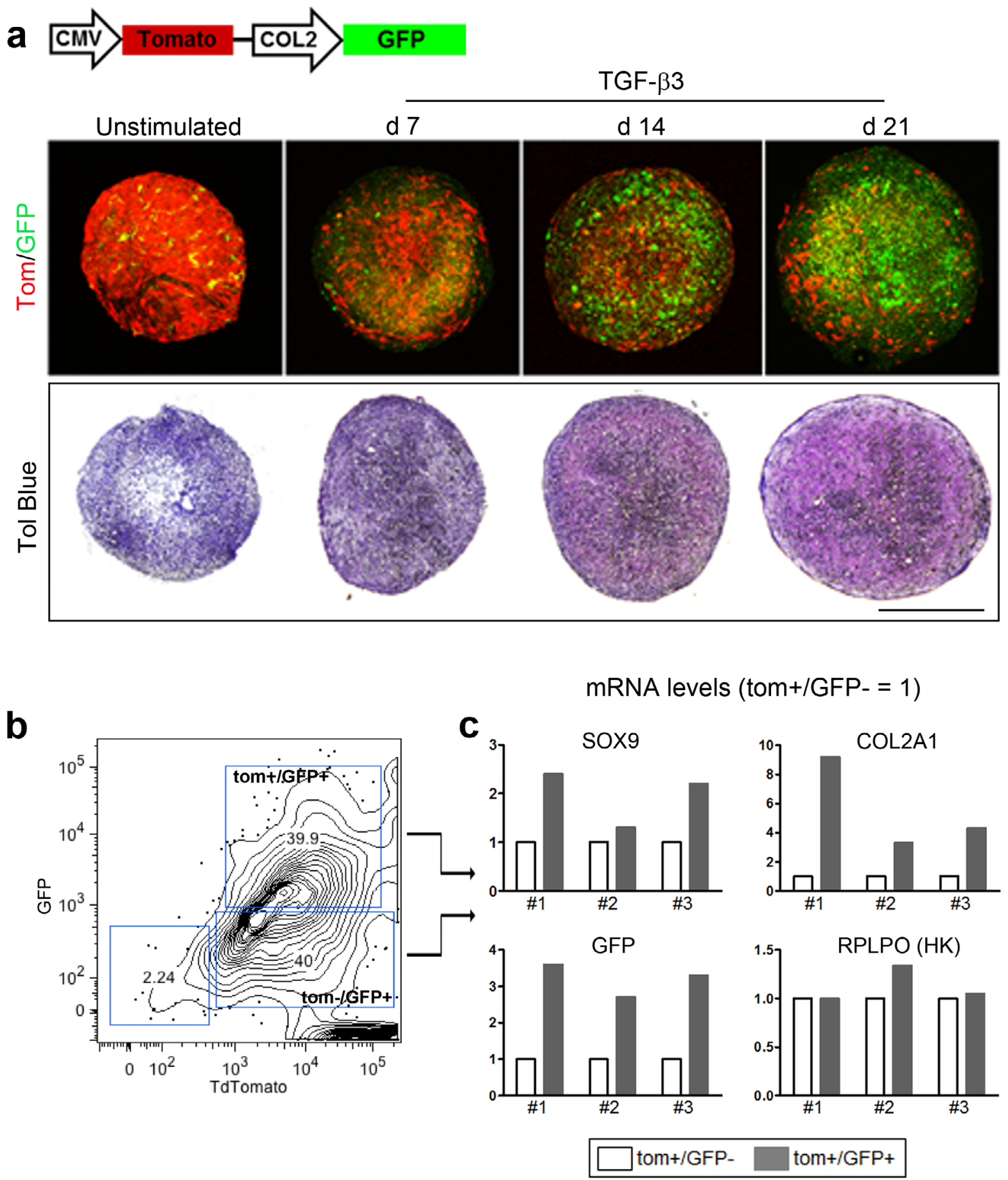

Fig. 2. Identification of chondrogenic cells in differentiating aggregate cultures of MSCs. (a) Upper panels: red/green fluorescence images of intact aggregates of BM-MSCs from a 9-year-old donor, modified with a dual fluorescence lentiviral reporter, Lv.CMV-tom/Col2-GFP. Lower panels: toluidine blue staining of aggregate sections at corresponding time points. (b) Representative flow cytometry contour plot showing the frequency of fluorescent cell populations in differentiating aggregates isolated at day 14. (c) Relative mRNA levels in sorted cell populations (from b) deriving from pooled aggregates of 3 separate equine donors, 2 (\#1), 9 (\#2) and 12 (\#3) years old. Scale bar: $500 \mu \mathrm{m}$. 
tdTomato+/GFP+ cell populations by FACS and analysed for expression of chondrogenic mRNAs (contour plot, Fig. 2b). Figure 2c shows expression levels in pooled aggregates of 3 separate MSC donors, indicating upregulation of SOX9 (1.3-2.4-fold) and COL2A1 (3.3-9.2-fold) in the tdTomato+/GFP+ fraction relative to the tdTomato+/GFP- fraction. GFP mRNA levels, included as a cell sort control, were also elevated ( 3 -fold), while the levels of the non-chondrogenic housekeeping gene, ribosomal protein lateral stalk subunit P0 (RPLP0), did not change between the cell populations.

Spatial variations in chondrogenic activity were further assessed by high-resolution (2-photon) imaging of $21 \mathrm{~d}$ aggregates of TGF- $\beta 3$-treated BMMSCs (Fig. 3). Aggregates were halved and imaged through the centre to obtain red (tdTomato) and green (GFP) image stacks that were analysed separately to determine fluorescence signal vs. depth (Fig. 3a). Line plot analysis showing fluorescence intensity profiles (along the $\mathrm{x}$ axis) was performed at varying y-plane depths (plots i-v, Fig. 3b). Fluorescence ratios $>2$ were marked green, denoting high chondrogenic activity, while ratios $<2$ were marked red, denoting lower/absent activity. Analysis revealed that highly chondrogenic cells were non-uniformly distributed, with most of the chondrogenic peaks located $(\sim 50$ $400 \mu \mathrm{m}$ ) beneath the aggregate surface (in both $\mathrm{x}$ and $y$ planes). This was most evident in plots $\mathrm{i}$ and $\mathrm{v}$ (y-plane depth $\leq 400 \mu \mathrm{m}$ ) and plots ii and iv (x-plane depth $0-250 \mu \mathrm{m})$. Areas of low chondrogenic activity (red) were also concentrated in the deepest regions of the aggregate, represented in plots ii-iv, $\sim 300$ $900 \mu \mathrm{m}$, although some chondrogenic cells were still present. These regional variations likely reflected the combined effects of oxygen, nutrient and TGF- $\beta 3$ gradients on chondrogenic differentiation within the 3D microenvironment.

A secretable luciferase reporter revealed marked variations in chondrogenic potential among MSC populations

For luminescence-based determination of chondrocyte differentiation, a lentiviral construct containing the same modified Col 2 promoter driving the expression of secreted Metridia luciferase (mLUC) and a constitutive EF1 $\alpha$ promoter driving GFP expression for normalisation of transduction efficiency were generated. Through luciferase assay of the conditioned media at various time points, it was assumed that Col2-Luc-reporter-labelled cells would enable longitudinal, non-invasive assessments

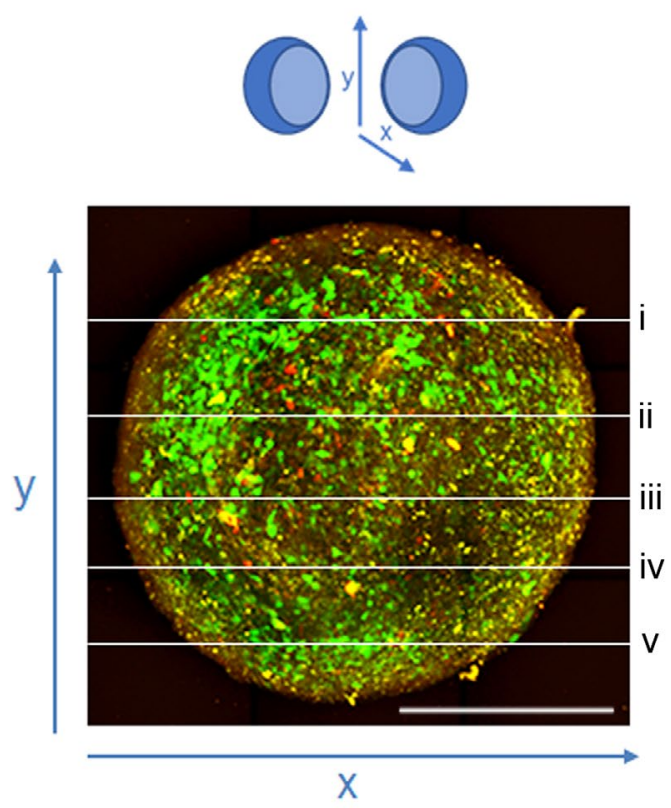

b
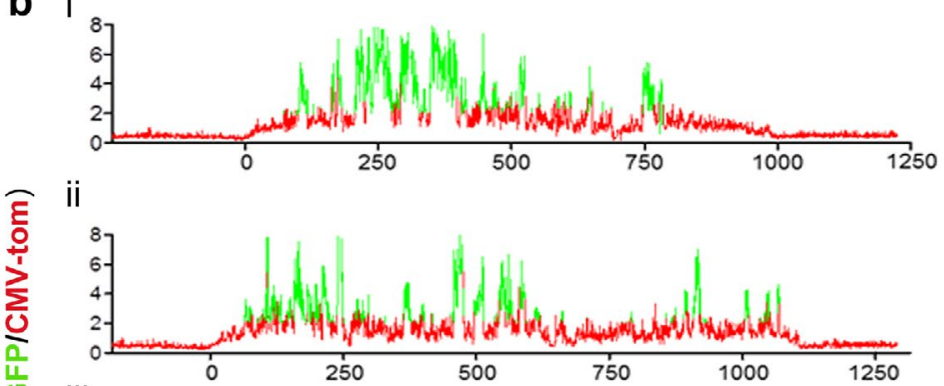

iii
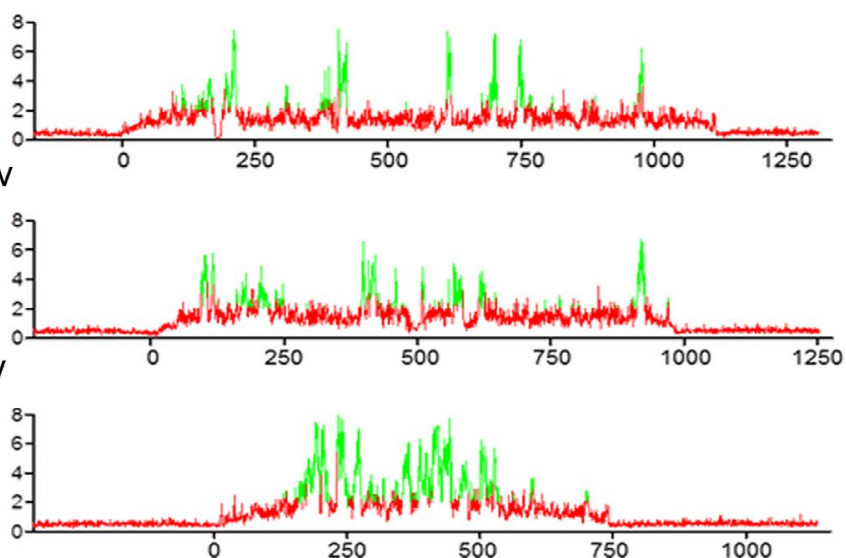

$X$ plane depth from surface $(\mu \mathrm{m})$

Fig. 3. Regional heterogeneity of chondrogenic cells in differentiating MSC aggregates. (a) Merged z-stack projection showing red/green fluorescence, captured by multi-photon imaging of MSC aggregates labelled with Lv.CMV-tom/Col2-GFP and treated with TGF- $\beta 3$ until day 21. Aggregates were cut in half and imaged through the centre (z-plane depth $=1500 \mu \mathrm{m})$. Scale bar: $500 \mu \mathrm{m}$. (b) Line plots, i-v, showing fluorescent pixel intensity vs. depth analysed using ImageJ software. Fluorescence ratios $>2$ are marked in green denoting high relative chondrogenic activity, while ratios $<2$ are marked in red denoting low/ absent activity. Analyses are representative of 4 BM-MSC aggregates. 
of differentiation in 3D culture systems that were predictive of overall chondrogenesis, determined by conventional endpoint assays.

Using cells obtained from the same equine donor, chondrogenic activities were compared among MSCs derived from bone marrow (BM), synovium (S) and adipose (A) tissues. MSCs were transduced with Lv.Col2-mLuc/EF1-GFP and grown in aggregate cultures and photopolymerisable PEGHA hydrogels (Fig. 4a), which are transplantable scaffolds compatible with cell-based cartilage repair (Sharma et al., 2007). To facilitate direct comparisons among cell types, activity was normalised to Lv.CMVmLuc/EF1-GFP-modified aggregates, cultured in parallel (Fig. 4a). Articular chondrocytes, also harvested from the same donor, were included as a reference for chondrogenic activity. Among MSC types, the luciferase profiles revealed a common trend in both aggregate and hydrogel cultures, with highest chondrogenic activity in BM-MSCs, followed by S-MSCs and A-MSCs at all time points (Fig. 4b,c). Differences among cell types were significant at day 21 in aggregate culture, with A-MSCs exhibiting lower activity as compared to other cells $(p<0.05$, Fig. 4 b), and at day 14 and 21 in PEG-HA cultures, where
BM-MSCs had higher activity than all other cell types $(p<0.05$, Fig. 4c). Somewhat surprisingly, activity in BM-MSCs was also higher than chondrocytes in aggregate cultures at day 14 and 21 and at all time points in PEG-HA cultures. The luciferase profiles were mostly consistent with the mRNA levels of the chondrogenic markers SOX9 and COL2A1 at the endpoint (day 21), indicating the same trend among MSC types (Fig. 4d,e). Similarly, toluidine blue staining intensities of cultures harvested at the endpoint reflected the superior chondrogenesis of BM-MSCs followed by S-MSCs and A-MSCs in both culture systems, in agreement with the luciferase data (Fig. 4f,g). The endpoint analysis also revealed similar chondrogenesis of BM-MSCs relative to chondrocytes in aggregates, also consistent with the luciferase reporter profile (Fig. $4 \mathbf{b}, \mathbf{d}, \mathbf{f}$ ). In contrast, chondrocytes in PEG-HA hydrogels had roughly equivalent matrix staining and > 2-fold higher levels of COL2A1 as compared to BM-MSCs, despite exhibiting lower luciferase activity. This discordance could potentially reflect differences in innate stabilities between chondrocyte and MSC phenotypes that were not detectable at the level of Col2 reporter activity.

a

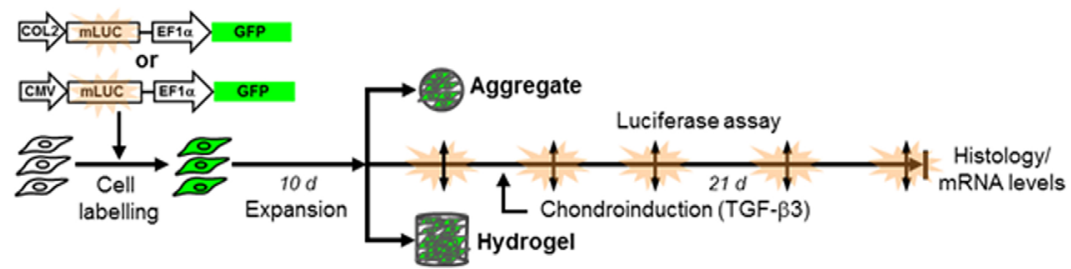

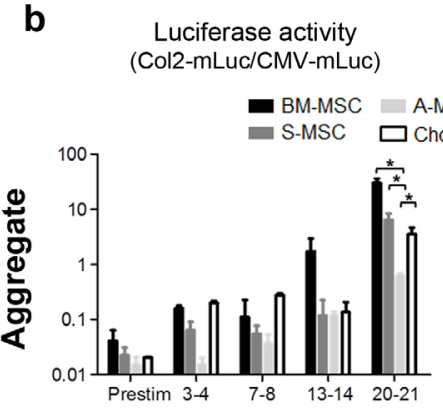

C

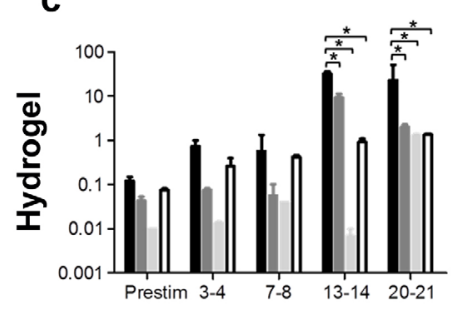

d

drocyte

mRNA levels (chondrocyte $=1$ )

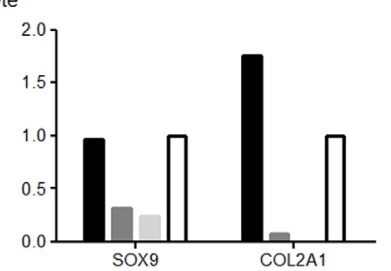

e

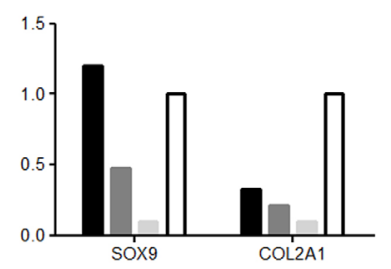

$\mathbf{f}$

Toluidine blue staining
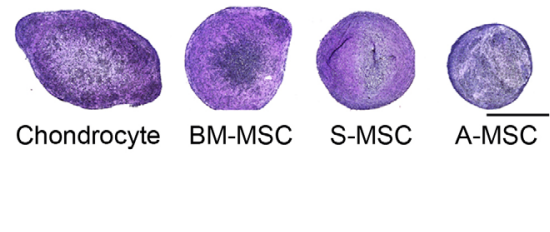

g

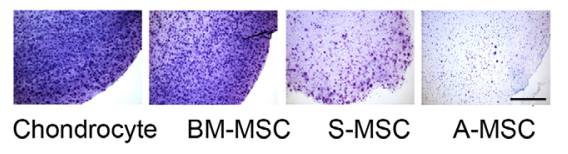

Fig. 4. Luciferase-based, real-time monitoring of chondrogenesis in equine cell populations cultured in aggregates and PEG-HA hydrogels. (a) Strategy for cell labelling, culture and analysis. Cells were harvested from a single equine donor (female, 2 years). (b,c) Secreted Metridia luciferase levels in the conditioned medium $24 \mathrm{~h}$ accumulation of TGF- $\beta 3$-treated aggregate and hydrogel cultures shown as a ratio of Col2mLuc/CMV-mLuc. Prestimulated controls (Prestim) represent luciferase levels in cultures without TGF- $\beta 3$ treatment (day 3-4). (d,e) Relative mRNA levels of pooled aggregates (5) and hydrogels (2) for each cell type at day 21 endpoint. $(\mathbf{f}, \mathbf{g})$ Toluidine blue staining of Lv-transduced aggregates and PEG-HA cultures at day $21 .{ }^{*} p<0.05$. Scale bars: $500 \mu \mathrm{m}$. 


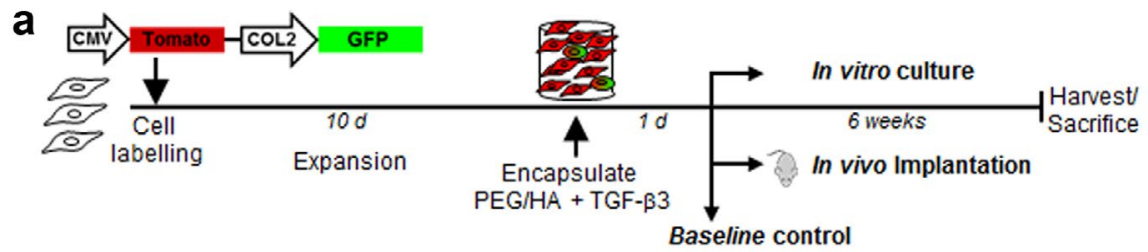

b
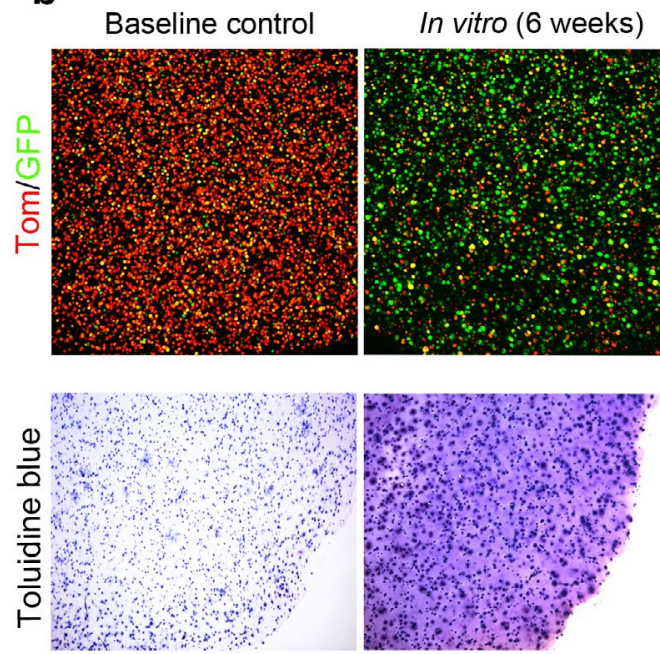

In vitro (6 weeks)
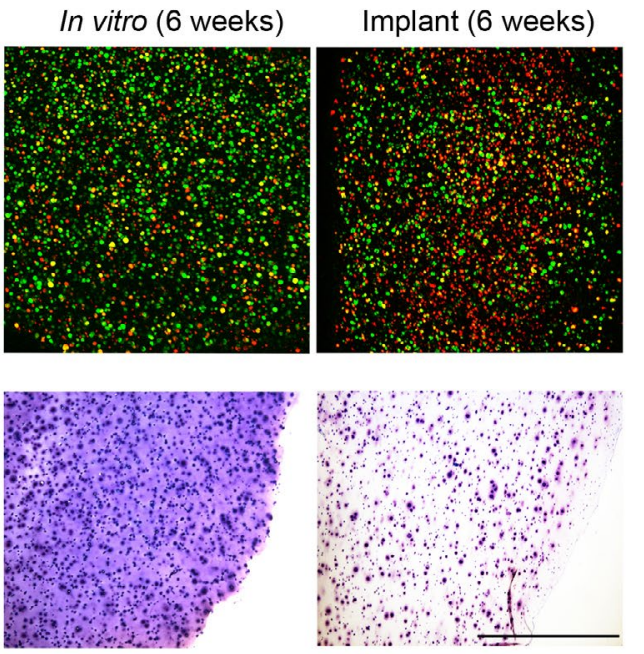

C Chondrogenic cells (\% total population)

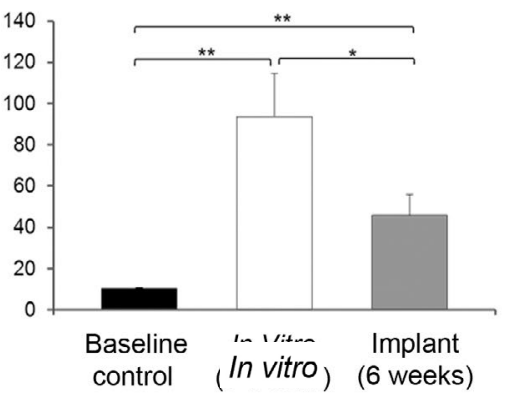

Fig. 5. Comparison of chondrogenic cell fates in PEG-HA hydrogels in vitro and in vivo using the dual fluorescence reporter, Lv.CMV-tom/Col2-GFP. (a) Strategy for cell labelling, encapsulation and in vitro culture/implantation. (b) Upper panels: red/green fluorescence images of Lv.CMV-tom/Col2GFP-transduced chondrocytes in PEG-HA hydrogels. Lower panels: toluidine blue staining of hydrogel sections at corresponding time points. (c) Cell counts performed by separate analyses of red and green channels from captured confocal images using ImageJ to determine the relative proportion of chondrogenic (Col2-GFP+) cells within the total cell population (CMV-tdTomato+). Values represent mean of 3 cultures/ implants for each group. ${ }^{*} p<0.05$; ${ }^{* *} p<0.005$. Scale bar: $500 \mu \mathrm{m}$.

Dual fluorescence reporting enabled long-term monitoring of chondrogenic cell fates in PEG-HA implants

To investigate the utility of using fluorescent reporter constructs to determine chondrogenic cell fates in vivo, a subcutaneous implantation model was used to track the phenotype of chondrocytes seeded onto PEG-HA scaffolds. Chondrocytes were labelled with Lv.CMV-tom/Col2-GFP, expanded in monolayer and seeded on to PEG-HA hydrogels encapsulated with $100 \mathrm{ng}$ of TGF- $\beta 3$. After $24 \mathrm{~h}$, the cell-loaded hydrogels were either harvested for analysis (baseline control group), cultured in vitro with continuous exposure to chondrogenic induction medium (in vitro group) or implanted subcutaneously in athymic mice (implant group) (Fig. 5a). Fluorescence image analysis of recovered hydrogels revealed that over $90 \%$ of the total cell population was positive for GFP following in vitro differentiation for 6 weeks, increasing from $10 \%$ in the baseline group $(p<0.005$; Fig. $5 \mathbf{b}$ upper panels and $\mathbf{c}$ ). This likely reflected redifferentiation of the chondrocyte's phenotype after monolayer expansion through prolonged culture in a 3D microenvironment with continuous exposure to TGF- $\beta 3$. After 6 weeks in vivo, $\sim 45 \%$ of the total cell population was GFP+, indicating that initial encapsulation with TGF- $\beta 3$ could partially restore the chondrocyte phenotype, but to a lesser degree than under controlled in vitro conditions (Fig. 5c, $p<0.05)$. In support of these findings, toluidine blue metachromasia indicated greater cellular differentiation under in vitro conditions, with intense staining in both peri- and extracellular regions (Fig. $5 \mathbf{b}$ lower panels). In contrast, recovered implants had less staining, which appeared to be restricted to pericellular regions, while in the baseline group, no significant metachromasia was present. Taken together, these findings indicated that lentiviralbased fluorescent reporters could be used to quantify chondrogenic cell populations in 3D scaffolds and evaluate cellular-level chondrogenesis, providing a platform to compare chondrogenic potencies among chondrocytes and progenitor cell populations in established in vitro and in vivo models.

\section{Discussion}

The presented results demonstrated the use of lentiviral reporter vectors as tools for quantification and spatial assessment of chondrogenesis in primary adult equine cell populations in 3D culture systems. Lentiviral vectors encoding either GFP or luciferase 
reporters under conditional activation of a modified Col2 promoter exhibited stable, chondrocyte-specific reporter activity in primary equine chondrocytes and MSCs undergoing TGF- $\beta 3$-induced chondrogenesis, correlating with histology and mRNA expression levels of COL2A1 and SOX9. Using dual reporter vectors that provided readouts of chondrogenic (Col2) and constitutive (CMV/EF1 $\alpha$ ) activity, it was possible to (i) discriminate chondrogenic vs. nondifferentiated cells in aggregate and PEG hydrogel culture systems, (ii) directly compare chondrogenic activities among primary cell populations and (iii) monitor chondrogenic cell fate in hydrogels following subcutaneous implantation in vivo.

For in vitro monitoring of chondrogenesis, the use of recombinant lentiviral reporter vectors offers several advantages for screening chondrogenic activity of primary cells. They provide stable transgene expression, enabling long-term monitoring of cell fate, and high transduction efficiency ( Zhang et al., 2002), reducing the need for additional ex vivo manipulations, such as cell sorting or antibiotic selection, that can potentially affect cell differentiation ( Cohen et al., 2006; Connell et al., 2016). Transducing titers can be generated with large insert sizes (up to $\sim 18 \mathrm{kbp}$ ) (Kumar et al., 2001), which allows for the inclusion of multiple reporter genes within single or multiple expression cassettes, enabling several cellular readouts from a single infection.

Using a dual fluorescence reporter vector, Lv.CMV-tom/Col2-GFP, the number of chondrogenic cells (tdTomato+/GFP+) increased in parallel with the level of toluidine blue staining over time in aggregate cultures of MSCs. Notably, despite continued exposure to TGF- $\beta 3$, large numbers of non-chondrogenic, tdTomato+/GFP- cells were visible at the endpoint (day 21), indicating that a significant population of MSCs exhibited poor or no differentiation within the culture system. This was consistent with the flow cytometric analysis after day 14, where approximately $50 \%$ of the total cell population was GFP+/tdTomato+. Although the persistence of non-differentiated cells within pellet cultures of MSCs is first reported in 1998 (Yoo et al., 1998), the proportion of chondrogenic cells and degree of uniformity within cultures are rarely considered. A non-uniform distribution of differentiating cells was found within TGF- 33 -stimulated cultures, with most of the highly chondrogenic cells located proximal $(\sim 400 \mu \mathrm{m})$ to, but not along, the aggregate edge. This may reflect an optimal oxygen level just beneath the pellet surface, as hypoxia (i.e. 2-5\% oxygen) increases bone marrow MSC chondrogenesis in pellet culture (Anderson et al., 2016; Boyette et al., 2014). Anderson et al. (2016) observe that the MSC response to hypoxia is enhanced in relatively chondrogenic donor preparations. In the present study, fewer cells with high chondrogenic activity were detected within the central regions, which may reflect impaired cellular function resulting from diffusion limitations within the densely packed aggregates. Indeed, tumour spheroids (> $500 \mu \mathrm{m})$ are frequently characterised by proliferation gradients, hypoxic regions and reduced cell viability leading to the formation of necrotic cores (Hirschhaeuser et al., 2010; Laurent et al., 2013; Zanoni et al., 2016). Thus, size and geometric constraints associated with aggregate (sphere)-based culture may mask the true chondrogenic potential of a cell population or chondrogenic factor and should be taken into consideration when performing a screening assay.

For direct, real-time comparisons of chondrogenic activity among cell populations and 3D culture systems, a Col2-driven secretable luciferase reporter was used to reveal greater TGF- $\beta 3$-mediated chondrogenesis of BM-MSCs relative to S-MSCs and A-MSCs in both aggregate and PEG-hydrogel culture models. Moreover, relative luciferase activity between the cell types remained constant over the differentiation time course and correlated with histologic and mRNA expression levels at the endpoint. Thus, secretable Col2-Luc reporter activity may serve as a potency marker that can predict chondrogenic differentiation of MSCs, providing the opportunity for modification of culturing protocols in real-time, to facilitate the generation of stable, functional cartilage by a particular cell type. This would be of particular benefit to tissue engineering manufacturing processes, which are currently constrained by long-term culturing protocols that rely on endpoint assessments of the final product (Roh et al., 2016).

While interpretation of the study's findings was limited to TGF- $\beta 3$-driven chondrogenesis from a single equine donor, the superiority of BM-MSCs over A-MSCs is also reported by others (Danisovic et al., 2009; Kohli et al., 2015; Vidal et al., 2008). However, contrary to our observations in equine cells, comparative studies demonstrate enhanced chondrogenesis of S-MSCs relative to BM-MSCs in humans (Shirasawa et al., 2006; Yoshimura et al., 2007) and rats (Sakaguchi et al., 2005). These differences may be attributable to variations of MSC phenotype among species or the use of different growth factor combinations for chondro-induction between studies. Intriguingly, among two very different 3D culture formats - high density aggregates or PEGHA suspension culture - the relative chondrogenic potentials among BM-, S- and A-MSCs did not change, suggesting that cell-cell adhesion and cell-HA interactions were not critical factors in determining the overall chondrogenic response of the cells to TGF- $\beta 3$ induction, in the absence of mechanical costimulation. However, for optimal chondrogenesis of each MSC type in both culture systems, it will be necessary to perform a broader investigation that incorporates other TGF- $\beta$ superfamily members, such as BMP-6 (Estes et al., 2006; Hennig et al., 2007) and BMP-7 (Kurth et al., 2007; Miyamoto et al., 2007; Shintani and Hunziker, 2007), which enhance chondrogenic differentiation of A-MSCs and S-MSCs, respectively. 
With the long-term goal of application in cartilage defects, the feasibility of using fluorescent reporters to monitor cellular-level chondrogenic cell fates in vivo by tracking Lv.CMV-tom/Col2-GFP-labelled chondrocytes in subcutaneously implanted PEG-HA hydrogels was tested. After 6 weeks in vivo, almost $50 \%$ of the cell population was chondrogenic (GFP+), significantly more than in monolayer-expanded cultures, but less as compared to PEG-HA hydrogels cultured in vitro. This was not surprising as in vivo implants received only a single $100 \mathrm{ng}$ bolus of TGF- $\beta 3$ during encapsulation, while TGF- $\beta 3$ stimulation in vitro was continuous, with repeated growth factor addition every $4 \mathrm{~d}$. Indeed, a single TGF- $\beta 3$ dose was also not sufficient for reproducible equine MSC differentiation in the same study (data not shown), reflecting the need for sustained growth factor delivery systems to promote cellular differentiation or long-term maintenance of the chondrocyte phenotype in vivo (Lam et al., 2015; ReyRico and Cucchiarini, 2017).

\section{Conclusions}

Variations associated with MSC isolation and culture, as well as poor characterisation of primary cell populations, have greatly impeded the clinical translation of MSCs in cartilage-repair applications (Tanavde et al., 2015). In large animal models, such as the horse -an essential preclinical model for orthopaedic conditions (Hurtig et al., 2011) - this problem is exacerbated by the lack of equine-specific antibodies, as well as the relatively small number of equine-specific gene and protein markers. In the present study, using equine cells as a test system, the utility of using transgenic lentiviral-based reporter vectors as tools for objective assessment of chondrogenesis in preclinical cell-based repair studies was demonstrated. The implementation of these reporters across laboratories will advance the development of standardised protocols and help promoting consensus among investigators with regard to cell types, scaffolds and chondro-induction methods for clinical translation of cell-based therapies for cartilage repair.

\section{Acknowledgements}

All authors declare no conflict of interest. Funding for this project was provided by the National Institute of Health grant R21AR069844 (GDP) and the University of Florida, Clinical and Translational Science Institute (CTSI) Pilot Project Award (GDP). The authors gratefully thank Dr Craig Moneypenny for his excellent technical assistance with flow cytometry and sorting. We also thank Lynda Schneider and Jonathan Wakim for their assistance with tissue processing and histology.

\section{References}

Anderson DE, Markway BD, Bond D, McCarthy HE, Johnstone B (2016) Responses to altered oxygen tension are distinct between human stem cells of high and low chondrogenic capacity. Stem Cell Res Ther 7: 154.

Bornes TD, Adesida AB, Jomha NM (2014) Mesenchymal stem cells in the treatment of traumatic articular cartilage defects: a comprehensive review. Arthritis Res Ther 16: 432.

Boyette LB, Creasey OA, Guzik L, Lozito T, Tuan RS (2014) Human bone marrow-derived mesenchymal stem cells display enhanced clonogenicity but impaired differentiation with hypoxic preconditioning. Stem Cells Transl Med 3: 241-254.

Cohen S, Samadikuchaksaraei A, Polak JM, Bishop AE (2006) Antibiotics reduce the growth rate and differentiation of embryonic stem cell cultures. Tissue Eng 12: 2025-2030.

Connell JP, Augustini E, Cheng S, Benavides OM, Ruano R, Jacot JG (2016) Effect of passage, sorting, and media on differentiation capacity and marker expression in amniotic fluid stem cells. Cel Mol Bioeng 9: 139-150.

Danisovic L, Varga I, Polak S, Ulicna M, Hlavackova L, Bohmer D, Vojtassak J (2009) Comparison of in vitro chondrogenic potential of human mesenchymal stem cells derived from bone marrow and adipose tissue. Gen Physiol Biophys 28: 56-62.

Dull T, Zufferey R, Kelly M, Mandell RJ, Nguyen M, Trono D, Naldini L (1998) A third-generation lentivirus vector with a conditional packaging system. J Virol 72: 8463-8471.

Estes BT, Wu AW, Guilak F (2006) Potent induction of chondrocytic differentiation of human adiposederived adult stem cells by bone morphogenetic protein 6. Arthritis Rheum 54: 1222-1232.

Goldberg A, Mitchell K, Soans J, Kim L, Zaidi R (2017) The use of mesenchymal stem cells for cartilage repair and regeneration: a systematic review. J Orthop Surg Res 12: 39.

He F, Chen X, Pei M (2009) Reconstruction of an in vitro tissue-specific microenvironment to rejuvenate synovium-derived stem cells for cartilage tissue engineering. Tissue Eng Part A 15: 3809-3821.

Hennig T, Lorenz H, Thiel A, Goetzke K, Dickhut A, Geiger F, Richter W (2007) Reduced chondrogenic potential of adipose tissue derived stromal cells correlates with an altered TGFbeta receptor and BMP profile and is overcome by BMP-6. J Cell Physiol 211: 682-691.

Hirschhaeuser F, Menne H, Dittfeld C, West J, Mueller-Klieser W, Kunz-Schughart LA (2010) Multicellular tumor spheroids: an underestimated tool is catching up again. J Biotechnol 148: 3-15.

Huang YZ, Xie HQ, Silini A, Parolini O, Zhang Y, Deng L, Huang YC (2017) Mesenchymal stem/ progenitor cells derived from articular cartilage, synovial membrane and synovial fluid for cartilage 
regeneration: current status and future perspectives. Stem Cell Rev 13: 575-586.

Hung CT, Henshaw DR, Wang CC, Mauck RL, Raia F, Palmer G, Chao PH, Mow VC, Ratcliffe A, Valhmu WB (2000) Mitogen-activated protein kinase signaling in bovine articular chondrocytes in response to fluid flow does not require calcium mobilization. J Biomech 33: 73-80.

Hurtig MB, Buschmann MD, Fortier LA, Hoemann CD, Hunziker EB, Jurvelin JS, MainilVarlet P, McIlwraith CW, Sah RL, Whiteside RA (2011) Preclinical studies for cartilage repair: recommendations from the International Cartilage Repair Society. Cartilage 2: 137-152.

Jayasuriya CT, Chen Q (2015) Potential benefits and limitations of utilizing chondroprogenitors in cell-based cartilage therapy. Connect Tissue Res 56: 265-271.

Johnstone B, Hering TM, Caplan AI, Goldberg VM, Yoo JU (1998) In vitro chondrogenesis of bone marrow-derived mesenchymal progenitor cells. Exp Cell Res 238: 265-272.

Kan A, Ikeda T, Saito T, Yano F, Fukai A, Hojo H, Ogasowara T, Ogata N, Nakamura K, Chung UI, Kawaguchi H (2009) Screening of chondrogenic factors with a real-time fluorescence-monitoring cell line ATDC5-C2ER: identification of sorting nexin 19 as a novel factor. Arthritis Rheum 60: 3314-3323.

Khan WS, Adesida AB, Tew SR, Longo UG, Hardingham TE (2012) Fat pad-derived mesenchymal stem cells as a potential source for cell-based adipose tissue repair strategies. Cell Prolif 45: 111-120.

Kim JH, Lee SR, Li LH, Park HJ, Park JH, Lee KY, Kim MK, Shin BA, Choi SY (2011) High cleavage efficiency of a $2 \mathrm{~A}$ peptide derived from porcine teschovirus-1 in human cell lines, zebrafish and mice. PLoS One 6: e18556.

Kohli N, Wright KT, Sammons RL, Jeys L, Snow M, Johnson WE (2015) An in vitro comparison of the incorporation, growth, and chondrogenic potential of human bone marrow versus adipose tissue mesenchymal stem cells in clinically relevant cell scaffolds used for cartilage repair. Cartilage 6: 252263.

Kumar M, Keller B, Makalou N, Sutton RE (2001) Systematic determination of the packaging limit of lentiviral vectors. Hum Gene Ther 12: 1893-1905.

Kurth T, Hedbom E, Shintani N, Sugimoto M, Chen FH, Haspl M, Martinovic S, Hunziker EB (2007) Chondrogenic potential of human synovial mesenchymal stem cells in alginate. Osteoarthritis Cartilage 15: 1178-1189.

Lam J, Lu S, Kasper FK, Mikos AG (2015) Strategies for controlled delivery of biologics for cartilage repair. Adv Drug Deliv Rev 84: 123-134.

Laurent J, Frongia C, Cazales M, Mondesert O, Ducommun B, Lobjois V (2013) Multicellular tumor spheroid models to explore cell cycle checkpoints in 3D. BMC Cancer 13: 73.

Livak KJ, Schmittgen TD (2001) Analysis of relative gene expression data using real-time quantitative
PCR and the 2(-delta delta $\mathrm{C}(\mathrm{T})$ ) method. Methods 25: 402-408.

Lo Monaco M, Merckx G, Ratajczak J, Gervois P, Hilkens P, Clegg P, Bronckaers A, Vandeweerd JM, Lambrichts I (2018) Stem cells for cartilage repair: preclinical studies and insights in translational animal models and outcome measures. Stem Cells Int 2018: 9079538.

Mackay AM, Beck SC, Murphy JM, Barry FP, Chichester CO, Pittenger MF (1998) Chondrogenic differentiation of cultured human mesenchymal stem cells from marrow. Tissue Eng 4: 415-428.

Martin-Pena A, Acebes A, Rodriguez JR, Sorribes A, de Polavieja GG, Fernandez-Funez P, Ferrus A (2006) Age-independent synaptogenesis by phosphoinositide 3 kinase. J Neurosci 26: 1019910208.

Matricali GA, Dereymaeker GP, Luyten FP (2010) Donor site morbidity after articular cartilage repair procedures: a review. Acta Orthop Belg 76: 669-674.

Matsumoto T, Okabe T, Ikawa T, Lida T, Yasuda H, Nakamura H, Wakitani S (2010) Articular cartilage repair with autologous mesenchymal stem cells. J Cell Physiol 225: 291-295.

McCarthy HE, Bara JJ, Brakspear K, Singhrao SK, Archer CW (2012) The comparison of equine articular cartilage progenitor cells and bone marrow-derived stromal cells as potential cell sources for cartilage repair in the horse. Vet J 192: 345-351.

McLeod CM, Mauck RL (2017) On the origin and impact of mesenchymal stem cell heterogeneity: New insights and emerging tools for single cell analysis. Eur Cell Mater 34: 217-231.

Miyamoto C, Matsumoto T, Sakimura K, Shindo H (2007) Osteogenic protein-1 with transforming growth factor-beta1: potent inducer of chondrogenesis of synovial mesenchymal stem cells in vitro. J Orthop Sci 12: 555-561.

Nathan S, Das De S, Thambyah A, Fen C, Goh J, Lee EH (2003) Cell-based therapy in the repair of osteochondral defects: a novel use for adipose tissue. Tissue Eng 9: 733-744.

Orth P, Madry H (2015). Complex and elementary histological scoring systems for articular cartilage repair. Histol Histopathol 30: 911-919.

Outani H, Okada M, Yamashita A, Nakagawa K, Yoshikawa H, Tsumaki N (2013) Direct induction of chondrogenic cells from human dermal fibroblast culture by defined factors. PLoS One 8: e77365. DOI: 10.1371/journal.pone.0077365.

Padmashali RM, Mistriotis P, Liang MS, Andreadis ST (2014) Lentiviral arrays for live-cell dynamic monitoring of gene and pathway activity during stem cell differentiation. Mol Ther 22: 1971-1982.

Palmer GD, Chao Ph PH, Raia F, Mauck RL, Valhmu WB, Hung CT (2001) Time-dependent aggrecan gene expression of articular chondrocytes in response to hyperosmotic loading. Osteoarthritis Cartilage 9: 761-770.

Pei M, Luo J, Chen Q (2008) Enhancing and maintaining chondrogenesis of synovial fibroblasts 
by cartilage extracellular matrix protein matrilins. Osteoarthritis Cartilage 16: 1110-1117.

Porter RM, Liu F, Ferreira E, Lunstord EP, Robichaud K, Evans CH (2012) Characterization of a fluorescence-luminescence reporter construct for extended evaluation of chondrogenesis in vitro and in vivo. Trans Orthop Res Soc 0559. Provide URL

Rey-Rico A, Cucchiarini M (2017) Smart and controllable rAAV gene delivery carriers in progenitor cells for human musculoskeletal regenerative medicine with a focus on the articular cartilage. Curr Gene Ther 17: 127-138.

Roelofs AS, Rocke JPJ, DeBari C (2013) Cellbased approaches to joint surface repair: a research perspective. OA and Cart 21: 892-900.

RohKH,Nerem RM, RoyK(2016)Biomanufacturing of therapeutic cells: state of the art, current challenges, and future perspectives. Annu Rev Chem Biomol Eng 7: 455-478.

Sakaguchi Y, Sekiya I, Yagishita K, Muneta T (2005) Comparison of human stem cells derived from various mesenchymal tissues: superiority of synovium as a cell source. Arthritis Rheum 52: 25212529.

Sharma B, Williams CG, Khan M, Manson $\mathrm{P}$, Elisseeff JH (2007) In vivo chondrogenesis of mesenchymal stem cells in a photopolymerized hydrogel. Plast Reconstr Surg 119: 112-120.

Shintani N, Hunziker EB (2007) Chondrogenic differentiation of bovine synovium: bone morphogenetic proteins 2 and 7 and transforming growth factor beta1 induce the formation of different types of cartilaginous tissue. Arthritis Rheum 56: 1869-1879.

Shirasawa S, Sekiya I, Sakaguchi Y, Yagishita K, Ichinose S, Muneta T (2006) In vitro chondrogenesis of human synovium-derived mesenchymal stem cells: optimal condition and comparison with bone marrow-derived cells. J Cell Biochem 97: 84-97.

Stokes DG, Liu G, Dharmavaram R, Hawkins D, Piera-Velazquez S, Jimenez SA (2001) Regulation of type-II collagen gene expression during human chondrocyte de-differentiation and recovery of chondrocyte-specific phenotype in culture involves Sry-type high-mobility-group box (SOX) transcription factors. Biochem J 360: 461-470.

Tanavde V, Vaz C, Rao MS, Vemuri MC, Pochampally RR (2015) Research using mesenchymal stem/stromal cells: quality metric towards developing a reference material. Cytotherapy 17: 1169-1177.

Veronesi F, Maglio M, Tschon M, Aldini NN, Fini M (2013) Adipose-derived mesenchymal stem cells for cartilage tissue engineering: state-of-the-art in in vivo studies. J Biomed Mater Res A 102: 2448-2466

Vidal MA, Robinson SO, Lopez MJ, Paulsen DB, Borkhsenious O, Johnson JR, Moore RM, Gimble JM (2008) Comparison of chondrogenic potential in equine mesenchymal stromal cells derived from adipose tissue and bone marrow. Vet Surg 37: 713-724.

Watson RS, Broome TA, Levings PP, Rice BL, Kay JD, Smith AD, Gouze E, Gouze JN, Dacanay
EA, Hauswirth WW, Nickerson DM, Dark MJ, Colahan PT, Ghivizzani SC (2013) scAAV-mediated gene transfer of interleukin-1-receptor antagonist to synovium and articular cartilage in large mammalian joints. Gene Ther 20: 670-677.

Wickham MQ, Erickson GR, Gimble JM, Vail TP, Guilak F (2003) Multipotent stromal cells derived from the infrapatellar fat pad of the knee. Clin Orthop Relat Res 412: 196-212.

Williams R, Khan IM, Richardson K, McCarthy HE, Analbelsi T, Singhrao SK, Dothwaite GP, Jones RE, Baird DM, Lewis H, Roberts S, Shaw HM, Dudhia J, Fairclough J, Briggs T, Archer CW (2010) Identification and clonal characterisation of a progenitor cell sub-population in normal human articular cartilage. PLoS One 5: e13246.

Yoo JU, Barthel TS, Nishimura K, Solchaga L, Caplan AI, Goldberg VM, Johnstone B (1998) The chondrogenic potential of human bone-marrowderived mesenchymal progenitor cells. J Bone Joint Surg Am 80: 1745-1757.

Yoshimura H, Muneta T, Nimura A, Yokoyama A, Koga H, Sekiya I (2007) Comparison of rat mesenchymal stem cells derived from bone marrow, synovium, periosteum, adipose tissue, and muscle. Cell Tissue Res 327: 449-462.

Zanoni M, Piccinini F, Arienti C, Zamangi A, Santi S, Polico R, Bevilacqua A, Tesei A (2016) 3D tumor spheroid models for in vitro therapeutic screening: a systematic approach to enhance the biological relevance of data obtained. Sci Rep 6: 19103.

Zhang XY, La Russa VF, Bao L, Kolls J, Schwarzenberger P, Reiser J (2002) Lentiviral vectors for sustained transgene expression in human bone marrow-derived stromal cells. Mol Ther 5: 555-565.

Zhou G, Lefebvre V, Zhang Z, Eberspaecher H, de Crombrugghe B (1998) Three high mobility group-like sequences within a 48-base pairenhancer of the Col2a1 gene are required for cartilagespecificexpression in vivo. J Biol Chem 273: 1498914997.

\section{Discussion with Reviewers}

Marcy Zenoby-Wong: How sorting of the Col2+ cells could be used to advance cartilage therapies?

Authors: Cell sorting offers the possibility of selecting homogenous populations of differentiated (Col2GFP+/CMV-tdTomato+) from less/non-differentiated (Col2-GFP-/CMV-tdTomato+) MSCs for evaluation in experimental models of cartilage repair. Comparative studies between sorted versus unsorted (mixed) populations may help determining the optimal differentiation state of effective MSC-based repair following implantation into cartilage defects. Current strategies in preclinical studies adopt various levels of pre-stimulation of MSCs with chondrogenic factors (Bornes et al., 2014; Goldberg et al., 2017); yet, how this conditioning, as it relates to cellularlevel differentiation status, affects cell engraftment, 
survival, integration and overall repair within a lesion is not extensively explored.

Marcy Zenoby-Wong: What would be the clinical consequence of using a heterogeneous population of MSCs?

Authors: Cellular heterogeneity is an inherent feature of primary MSC populations and poses a significant hurdle for cartilage regeneration therapies. At present, pre-clinical studies fail to extend beyond proof-of-concept due to a poor characterisation of MSC populations and the lack of standardised methods for quantifying chondrogenic potential (Tanavde et al., 2015). Consequently, repair studies have yet to demonstrate efficacy and the contribution of implanted MSCs to repair tissue is poorly understood. Clinically, heterogeneity in the cellular composition of MSC preparations will lead to inconsistent repair and unacceptably high variability in patient outcome. Efforts to reduce or control cellular heterogeneity, through the development of selection-based tools that enable quantification of proliferative capacity and multipotency, will be needed for reparative strategies involving MSCs for mainstream application.

Chris Evans: Are the authors surprised that $18 \%$ of synoviocytes express GFP from a Col 2 promoter? Would it be possible to sort these cells to determine whether they are spontaneously chondrogenic?

Authors: While the synovium is a source of stem cells with chondrogenic potential (Jones and Pai, 2012, additional reference), the study's results inferred that there was a resident cell subpopulation with a chondrocytic phenotype in primary cultures of equine synoviocytes that did not require derivation through cell expansion and stimulation with defined chondro-inductive growth factors. This finding was not a complete surprise as a fate mapping study shows that adult chondrocytes and synovial fibroblasts emerge from a common progenitor during development of synovial joints (Koyama et al., 2008, additional reference). Roelofs et al. (2017, additional reference) demonstrate that endogenous populations of growth differentiation factor 5 (GDF5)+ cells in the joint interzone contribute to both synovial hyperplasia and cartilage repair in vivo. Interestingly, in osteoarthritis cartilage, pannus-like soft tissue also contains cells expressing type II collagen and aggrecan, suggesting repair by cells of synovial origin in the early stage disease (Yuan et al., 2004, additional reference). These reports are in line with the present study on osteoarthritis in equine joints where extensive areas of contact between synovium and lesional as well as non-lesional articular cartilage are observed, suggesting direct, physical remodelling of cartilage by synovial tissues. Further investigation will be necessary to determine whether the synovialderived Col2-GFP cells identified in the present study were spontaneously chondrogenic and served as a potential source for cartilage repair.

\section{Additional References}

Jones BA, Pei M (2012) Synovium-derived stem cells: a tissue-specific stem cell for cartilage engineering and regeneration Tissue Eng Part B Rev 18: 301-311.

Koyama E, Shibukawa Y, Nagayama M, Sugito H, Young B, Yuasa T, Okabe T, Ochiai T, Kamiya N, Rountree RB, Kingsley DM, Iwamoto M, EnomotoIwamoto M, Pacifici M (2008) A distinct cohort of progenitor cells participates in synovial joint and articular cartilage formation during mouse limb skeletogenesis. Dev Biol 316: 62-73.

Roelofs AJ, Zupan J, Riemen AHK, Kania K, Ansboro S, White N, Clark SM, De Bari C (2017) Joint morphogenetic cells in the adult mammalian synovium. Nat Commun 8: 15040.

Yuan G-H, Tanaka M, Masuko-Hongo K, Shibakawa A, Kato T, Nishioka K, Nakamura H (2004) Characterization of cells from pannus-like tissue over articular cartilage of advanced osteoarthritis. Osteoarthritis Cartilage 12: 38-45.

Editor's note: The Scientific Editor responsible for this paper was Martin Stoddart. 